Published in "International Journal of Electronic Commerce 23(1): 85-109, 2019" which should be cited to refer to this work.

\title{
How Do the Global Stock Markets Influence One Another? Evidence from Finance Big Data and Granger Causality Directed Network
}

\author{
Yong Tang,(0) Jason Jie Xiong, Yong Luo, and Yi-Cheng Zhang
}

\begin{abstract}
The recent financial network analysis approach reveals that the topologies of financial markets have an important influence on market dynamics. However, the majority of existing Finance Big Data networks are built as undirected networks without information on the influence directions among prices. Rather than understanding the correlations, this research applies the Granger causality test to build the Granger Causality Directed Network for 33 global major stock market indices. The paper further analyzes how the markets influence one another by investigating the directed edges in the different filtered networks. The network topology that evolves in different market periods is analyzed via a sliding window approach and Finance Big Data visualization. By quantifying the influences of market indices, 33 global major stock markets from the Granger causality network are ranked in comparison with the result based on PageRank centrality algorithm. Results reveal that the ranking lists are similar in both approaches where the U.S. indices dominate the top position followed by other American, European, and Asian indices. The lead-lag analysis reveals that there is lag effects among the global indices. The result sheds new insights on the influences among global stock markets with implications for trading strategy design, global portfolio management, risk management, and markets regulation.
\end{abstract}

KEY WORDS AND PHRASES: Finance Big Data, Granger causality directed network, global stock markets, financial network analysis, data visualization, trading strategy, market regulation, risk management.

\section{Introduction}

Financial markets, including stock markets, are extremely complicated systems in which participants are playing various roles with asymmetric access to information at different market levels. The success and failure of financial markets have significant influences on the economies. Recent financial crises and market crashes urge practitioners and scholars to reevaluate the markets and understand the fundamental dynamics that the traditional financial theories fail to reveal. With the help of complex network theory, it is possible to model and extract the network topological structures to reveal hidden information and relationships among financial markets and assets. This financial network analysis approach benefits portfolio management, risk management, quantitative trading, and other financial practices by providing better understandings as well as visualizations of market dynamics. 
Financial market is considered an extremely complex system supported by various information technology innovations, including automated trading [26], off-exchange trading [20], and crowd-based stock selection [36]. Although the information is critical in the financial markets [16, 46], recent years have witnessed an emerging development of network science in various financial markets [54]. From Information Systems perspective, financial network analysis is an emerging method to analyze financial risks [48], financial cycle [60], stock market perspective [49], and risk spillover network [74]. However, based on current research of financial networks topologies, the networks are usually undirected graphs constructed from correlations among the price time series. Due to the lack of capability in revealing the information of mutual influences among the stocks, it is challenging to answer questions such as how one stock is causal to another stock, or which stock leads or lags to another stock. As correlation does not imply causation, other methods are needed to construct directed networks to catch the embedded causal relationships among the interinfluences of stocks. The study provides new tools to traditional finance studies, adds new insights to the undirected financial networks analysis research, and further provides implementations to research and practices.

The economies around the world are influencing one another due to globalization. It is thus essential to understand the dynamics of global markets. In this paper, we investigate the global stock markets comprising 33 market indices of major stock markets using Granger causal testing and lead/lag correlation to build directed networks and quantify the global markets dynamics. Overall, there are three research questions:

Research Question 1: Do Granger causality and lead/lag exist significantly in the global stock markets?

Research Question 2: What are the properties of those directed networks via Finance Big Data visualization?

Research Question 3: How do the major market indices influence one another and their importance in the network?

\section{Literature Review}

Financial systems are typical complex systems with a large number of heterogeneous participants interacting with one another in nonlinear ways. For global stock markets, it is essential to understand the interdependent relationships among the stocks. Using the price time series of a portfolio, the price correlation matrix, which indicates how assets are interacting with one another, can be built to further construct the correlation-based asset networks [62]. With these networks, the applications of the network analysis from complex network theory and random matrix theory could extract hidden information embedded in the behaviors of assets. Significant advancements have been made in the past few years focusing on these 
directions with many nontrivial empirical findings and applications to market crisis study, portfolio optimization, risk management, and trading strategy design. These achievements, compared to traditional economics and finance approaches, bring significant new insights into the understandings of the market structures and behaviors.

Many recent financial network analysis studies have been conducted on a variety of stock markets around the world, such as Brazil [68], China [32], South Korea [57], New Zealand [64], United States [61], Iran [52], Turkey [22], Russia [71], Sweden [42], Germany [11], European markets [14], and global markets [56]. The body of literature on correlation and network studies of financial markets are growing. This shows a great practical usages in both empirical studies and modeling the correlations and connectedness based on price information, as discussed in Billio et al. [7] and Podobnik et al. [63]. Besides the stock market, the real estate stock market is studied in Wang and Xie [73], and foreign exchange markets were studied in Fenn et al. [28] and Jang, Lee, and Chang [43]. As an extension of recent advances of social sentiment studies in finance, Zhang et al. [77] propose a stock price prediction method using the network structure properties with social sentiments. In Farmer et al. [27], a vision to model the financial markets and economic systems as coupled networks of agents are proposed to combine the powers of both complex network theory and computational multiple agent simulations. In a recent 2016 Science paper, Battiston et al. [4] argue that concepts from complexity theory like networks are necessary and have significant potentials to anticipate financial crises because the economies and financial systems are becoming highly connected [4]. The studies of network structure and the related properties and the dynamics provide new insights for financial market regulators for better policy decision makings $[3,63,67]$.

In financial network analysis, there has been some work on the relationships between economic entities like countries, companies, and board directors. For example, Battiston and Catanzaro [3] find that the network of board directors of big companies shows a small-world feature. Glattfelder [33] and Vitali, Glattfelder, and Battiston [70] investigated the corporate control relationships from the perspective of ownership networks extracted from the shareholder data. Several papers research the international world trade networks in which countries are vertices and the international import/export of goods among countries are used to build edges [5, 45]. All these works, in macro levels, depict the relationships of large economic entities, and the results are inspirational for macro trading. Furthermore, as a method of Financial Big Data, financial network analysis provides tools for revealing the topological structures of financial markets. To enhance the capability of financial network analysis, it would be interesting to apply it with other big data approaches using multiple sources of data, including price data, stock profiles, financial filings, and sentiments in social media [1, 66]. In the research conducted by Boginski, Butenko, and Pardalos [8], the degree distribution of the financial market is studied, and the statistical results show that the power law model is valid in financial networks. They 
also reveal that network structures are stable over time intervals, and parameters such as edge density increases in recent years indicate that stocks are influencing one another in the U.S. stock market. In the research conducted by Caldarelli et al. [13], the authors report that financial networks are extracted not only from stock prices but also from board director and stock ownership. These results show scale-free properties. Chen et al. [17] further discuss the relationship between the interindustry closeness and returns industry in industrial level and the stock centrality and stock returns in stock level. The global stock markets are not only important for the individual country but also entangled with significant influences with one another. The understanding of the dynamics of global stock markets is essential to industrial practices as well as to the policymakers for a better global economy [5, 25, 45]. In the traditional finance approaches, the dynamics of global markets have been studied in various aspects, such as effects of the herding $[18,37]$ driving factors, risk and predicting of market returns [19, 29, 38], co-movement [31], interdependence, transmission dynamics [50], correlation [35], and structure and performance of global markets [6]. However, there is still a lack of study on the directed network properties of global markets with focus on causality and lead/lag effects to reflect the influencing relationships among global markets. It is interesting to explore from new perspective and add new evidences to further verify the effects, factors, predictions, and dynamics. Online Appendix provides a summary of selected representative literatures in the logic of complex network theory, financial network analysis, global stock market studies, Granger and lead/lad, and applications.

In this study, we focus on the global stock market network constructed from price information. The market indices are treated as the vertices, whereas the relationships are translated as edges between stock markets. The contribution of the research is in providing findings of global stock market directed networks built from Granger causality information and lead/lag effects. There is some relevant research that applies the Granger causality tests in the study of network structures of financial markets. Using the measurements of Granger causality networks based on monthly returns, the study [7] shows that the financial institutional sectors (hedges funds, banks, brokers, and insurance companies) interrelate, and banks represent more important roles. The international business cycles are studied in Caraiani [15] using Granger causality network approach. It reveals that the United States plays important roles in subnetworks composed by G7 and Organisation for Economic Co-operation and Development countries. Instead of using gross domestic product (GDP) data, we use all major global stock markets indices data and focus on the dynamics of stock market behavior. The Chinese stock market is studied using the cointegration approach, and the structures are studied in Tu [69], where they apply the Engle-Granger test to extract the subnetworks of Chinese stock market. The study on the Granger causality networks of 20 developed markets is carried out in Výrost, Lyócsa, and Baumöhl [72], and the survival ratio measurement is used to study the stability. In Kenett et al. [47], a metacorrelation, 
which is the correlation of the index return and the market mean correlation, is proposed to study the components of the Dow Jones Industrial Average (DJIA). Authors apply the Granger causality test to validate the results and find that the index returns correlate with the mean correlations. In Zheng et al. [78], a dynamic causality index is used to measure the market shifts for the U.S. stock market as well.

\section{Data Analysis and Discussion}

\section{Whole Period}

Using the return data over the whole period, the Granger causality test is conducted for all index pairs. Details of the research methodology of Granger causality, ADF and Unit Root Test, and Data Setting Introduction are presented in the online Appendix. The $F$-statistic and critical values are calculated. Granger binary network is generated where vertices are indices and the directed edges are weighted as 1 if $F$-statistic is larger than critical values, as

$$
\vec{e}_{i j}=\left\{\begin{array}{l}
1 \text { if } F>c, \\
0 \text { otherwise, }
\end{array}\right.
$$

where $F$ is the $F$-statistic and $c$ represents the critical value. If $F>c$, as we described earlier, $I_{i} \rightarrow I_{j}$, that is, $I_{i}$ granger causes $I_{j}$, then a directed edge $\vec{e}_{i j}$ is established from $I_{i}$ to $I_{j}$. Figure 1 plots the average correlation of each sliding windows. In Figure 2, the granger network of 33 indices calculated from the return data of the whole period is presented. The total number of edges satisfying $F>c$ is 727 of 1,089 possible directed edges. In other words, the network has an edge density of 0.6676 . For index $I_{i}$, which is connected by directed edges to other indices, we denote the in-degree as $d_{i}^{i n}$, outdegree as $d_{i}^{\text {out }}$, and total-degree as $d_{i}^{\text {total }}=d_{i}^{\text {in }}+d_{i}^{\text {out }}$. For a given index, $d_{i}^{\text {in }}$ indicates how many other indices granger cause $I_{i}$. $d_{i}^{\text {out }}$ indicates how many other indices are granger caused by $I_{i}$, more precisely,

$$
d_{i}^{\text {in }}=\left|\vec{e}_{k i}\right|_{k \neq i} \text { and } d_{i}^{\text {out }}=\left|\vec{e}_{i}\right|_{k \neq i} .
$$

To quantify the influence for each vertex, the influence factor introduced in Caraiani [15] is adopted, in which a Granger causality network is constructed by using the GDP data. Based on the granger network, the influence of each vertex (country) is measured as the relative influence factor (IF):

$$
I F_{i}=\frac{d_{i}^{\text {out }}-d_{i}^{\text {in }}}{d_{i}^{\text {in }}-d_{i}^{\text {out }}} .
$$

It shows that Granger causal network better predicts the fluctuations, and the United States has the largest influence over other countries, which 


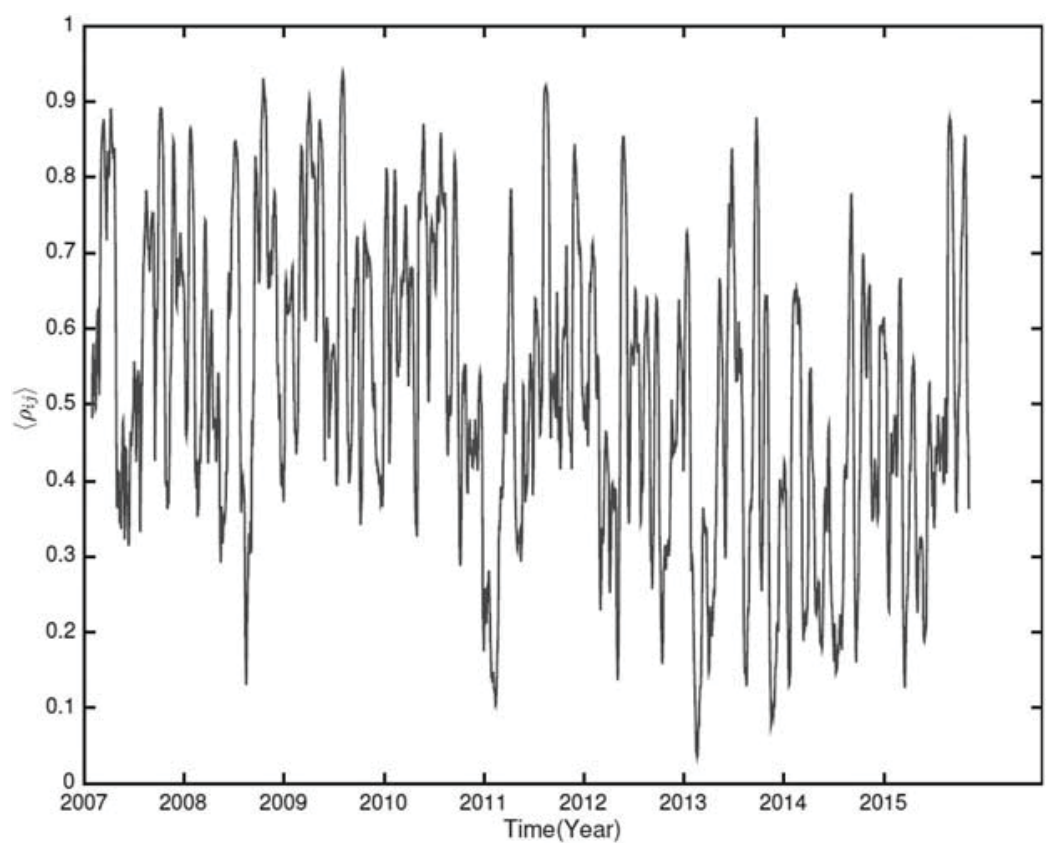

Figure 1. The Average Correlation $\left\langle\rho_{i j}\right\rangle$ for Each Sliding Time Window of 20 Trading Days in the Whole Study Period. Note. We see that the correlations are positive and fluctuate dramatically.

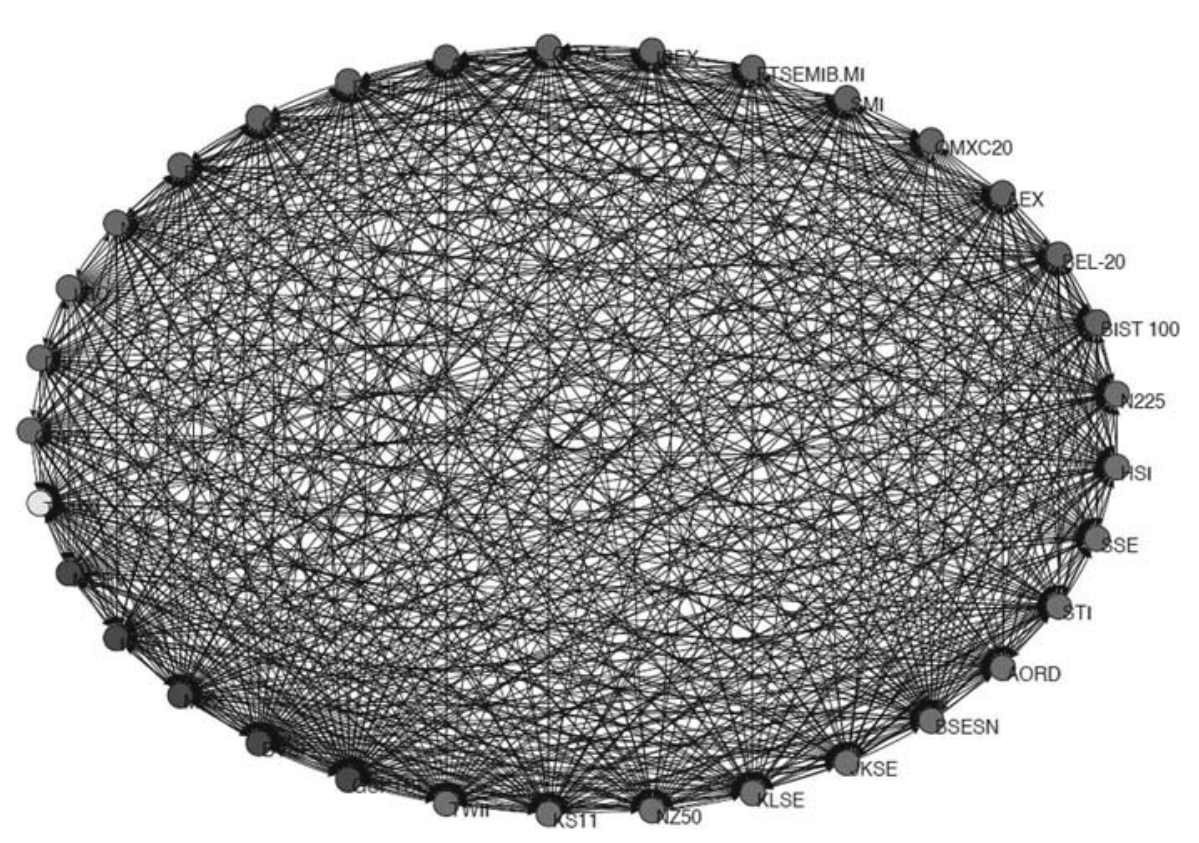

Figure 2. The Granger Binary Network of 33 Indices Calculated From the Whole Period 
agrees with our findings. The same measurement is also used in $\mathrm{Tu}$ [69] to study the influence of different industrial sectors. Using the same method, we present the degree information and influence factors for all 33 indices in Table 1. We sort the rows in descending order according to the influence factor $I F_{i}$. For different regions, we average the values and present them in Table 2. Four indices-IXIC (NASDAQ), GSPC (S\&P500), DJI, and NYA (NYSE) - rank top four positions. This shows these U.S.-based indices are the most influential vertices in the whole global granger network. It also

Table 1. The $d_{i}^{\text {in }}, d_{i}^{\text {out }}, d_{i}^{\text {total }}, I F_{i}$ for Each Index in the Granger Causality Network in the Descending Order of $I F_{i}$.

\begin{tabular}{|c|c|c|c|c|c|c|}
\hline Tick & Country & Region & $d_{i}^{i n}$ & $d_{i}^{\text {out }}$ & $d_{i}^{\text {total }}$ & $I F_{i} \downarrow$ \\
\hline IXIC & US & American & 5 & 32 & 37 & 0.7297 \\
\hline GSPC & US & American & 10 & 30 & 40 & 0.5000 \\
\hline DJI & US & American & 10 & 30 & 40 & 0.5000 \\
\hline NYA & US & American & 11 & 30 & 41 & 0.4634 \\
\hline MERV & Argentina & Americas & 10 & 27 & 37 & 0.4595 \\
\hline IPSA & Chile & Americas & 16 & 26 & 42 & 0.2381 \\
\hline BEL-20 & Belgium & Europe & 18 & 27 & 45 & 0.2000 \\
\hline AEX & Netherlands & Europe & 18 & 25 & 43 & 0.1628 \\
\hline GDAXI & Germany & Europe & 19 & 26 & 45 & 0.1556 \\
\hline IBEX & Spain & Europe & 17 & 23 & 40 & 0.1500 \\
\hline $\begin{array}{l}\text { FTSEMIB. } \\
\text { MI }\end{array}$ & Italy & Europe & 17 & 22 & 39 & 0.1282 \\
\hline SMI & Switzerland & Europe & 18 & 23 & 41 & 0.1220 \\
\hline MXX & Mexico & Americas & 25 & 31 & 56 & 0.1071 \\
\hline $\mathrm{FCHI}$ & France & Europe & 20 & 24 & 44 & 0.0909 \\
\hline GD.AT & Greece & Europe & 21 & 25 & 46 & 0.0870 \\
\hline FTSE & UK & Europe & 20 & 23 & 43 & 0.0698 \\
\hline BSESN & India & Asia & 24 & 27 & 51 & 0.0588 \\
\hline GSPTSE & Canada & Americas & 28 & 30 & 58 & 0.0345 \\
\hline OMXC20 & Denmark & Europe & 20 & 18 & 38 & -0.0526 \\
\hline KS 11 & Korea & Asia & 26 & 23 & 49 & -0.0612 \\
\hline BVSP & Brazil & Americas & 33 & 28 & 61 & -0.0820 \\
\hline ATX & Austria & Europe & 25 & 21 & 46 & -0.0870 \\
\hline JKSE & Indonesia & Asia & 26 & 21 & 47 & -0.1064 \\
\hline BIST 100 & Turkey & Europe & 24 & 18 & 42 & -0.1429 \\
\hline $\mathrm{HSI}$ & Hong Kong & Asia & 27 & 18 & 45 & -0.2000 \\
\hline STI & Singapore & Asia & 29 & 19 & 48 & -0.2083 \\
\hline TA 100 & Israel & $\begin{array}{l}\text { Middle } \\
\text { East }\end{array}$ & 31 & 15 & 46 & -0.3478 \\
\hline N225 & Japan & Asia & 29 & 14 & 43 & -0.3488 \\
\hline AORD & Australian & Asia & 28 & 11 & 39 & -0.4359 \\
\hline KLSE & Malaysia & Asia & 31 & 12 & 43 & -0.4419 \\
\hline NZ50 & $\begin{array}{l}\text { New } \\
\text { Zealand }\end{array}$ & Asia & 32 & 10 & 42 & -0.5238 \\
\hline SSE & China & Asia & 29 & 9 & 38 & -0.5263 \\
\hline TWII & Taiwan & Asia & 30 & 9 & 39 & -0.5385 \\
\hline
\end{tabular}


Table 2. The Number of Countries, $\left\langle d_{i}^{\text {in }}\right\rangle,\left\langle d_{i}^{\text {out }}\right\rangle,\left\langle d_{i}^{\text {total }}\right\rangle$, and $\left\langle I F_{i}\right\rangle$ for Five Regions of the Global Indices.

\begin{tabular}{lccccc} 
Region & Country & $\left\langle d_{i}^{\text {in }}\right\rangle$ & $\left\langle d_{i}^{\text {out }}\right\rangle$ & $\left\langle d_{i}^{\text {total }}\right\rangle$ & $\left\langle I F_{i}\right\rangle$ \\
\hline American & 4 & 9 & 30.5000 & 39.5000 & 0.5483 \\
Europe & 12 & 19.7500 & 22.9167 & 42.6667 & 0.0736 \\
Asia & 11 & 28.2727 & 15.7273 & 44 & -0.3029 \\
Americas & 5 & 22.4 & 28.4000 & 50.8000 & 0.1514 \\
Middle East & 1 & 31 & 15 & 46 & -0.3478 \\
\hline
\end{tabular}

agrees with the findings in Caraiani [15] that the U.S. economy places top position in the GDP-based Granger network. Second, we find that European countries dominated the middle part of the ranking after the United States but followed by the Asian countries.

The average $i n$-degree $<d^{i n} \geq 22.0303$, as in-degree and out-degree is symmetrical, so we have the same value for $\left\langle d^{\text {out }}\right\rangle$ as 22.0303. By averaging all $\left\langle I F_{i}\right\rangle$, the average influence factor is $\left\langle I F_{i} \geq 0.0047\right.$, which indicates that the there is a positive overall influence factor among the indices. For different regions, we summarize the average values in Table 2, and find that the United States ranks first with a dominated influence factor followed by Americas, Europe, Asia, and Middle East. This shows that Asian countries with a small average influence factor $<I F_{i} \geq-0.3029$ are less influential in the global stock market. This adds new insights of the global stock market dynamics, indicating that the global influence is not only related to the economy but also deeply rooted with the stock market price dynamics in terms of causality.

As shown in Figure 2, the binary network is very dense with 727 edges, it is necessary to filter the network and adapt the weights of the edges. In Caraiani [15], authors use the $F$-statistic value to assign different weights to the edges. The basic idea is that a weight value is assigned to the edge based on the relevant significance level. However, the shortcoming is that all $F$-statistic information is lost. In Figures 3(a) and 3(b), we present the Granger networks with the top 5 percent and 25 percent edges with largest $F$-statistic values. Our results in these two filtered networks show that the four U.S.-based indices are the most influential indices with direct influences over most of the other indices. Meanwhile, they are nearly independent from the remaining parts without inbound edges. The indices of Americas mainly influence the Asian countries. The European indices are influenced by both U.S. and Americas indices, and they influence mainly the Asian indices. For Asian indices, they have nearly no influences on other indices and not all of them are greatly influenced by the rest indices, even the top 25 percent edges are included as shown in Figure 3(b). For individual index, NZ50 (New Zealand) are the most Granger caused by DJI (United States) and NYA (United States). The FTSE (London, UK) is mainly influenced by the four U.S. indices. In Asia, N225 (Japan), AORD (Australia), NZ (New Zealand), and JKSE 


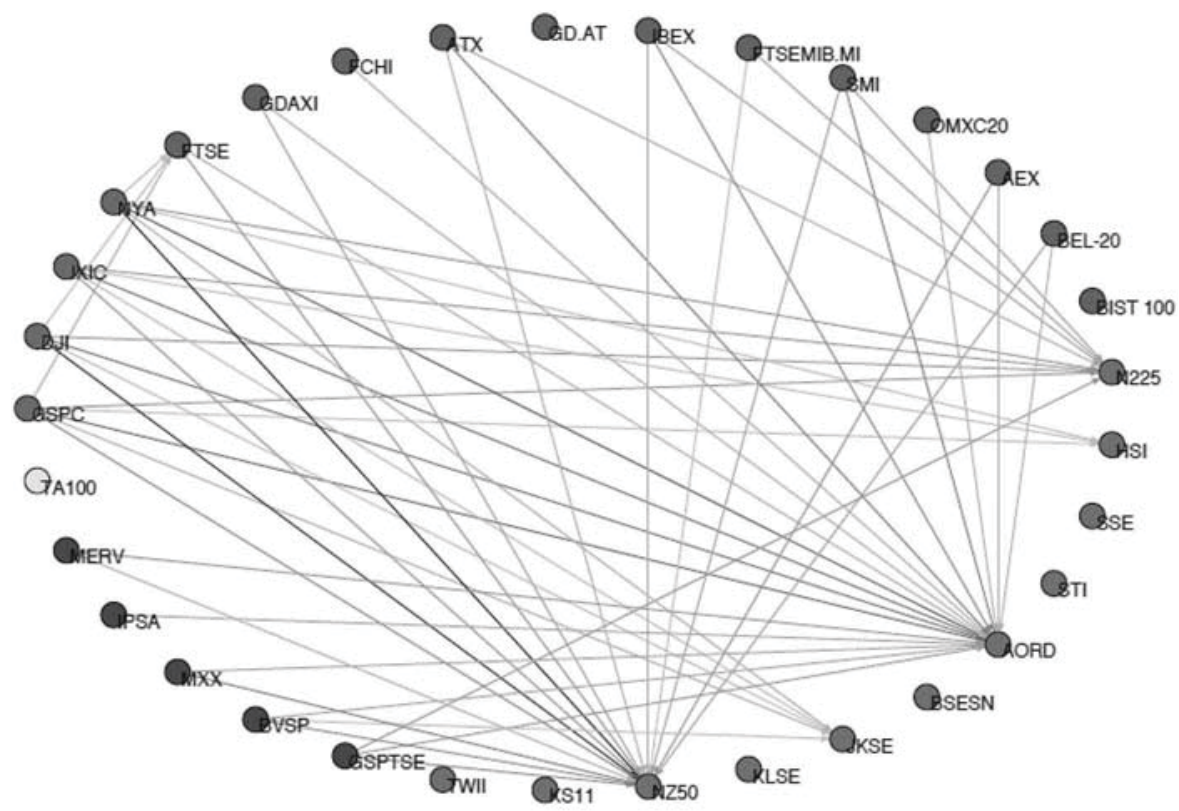

(a) Top $5 \%$ edges

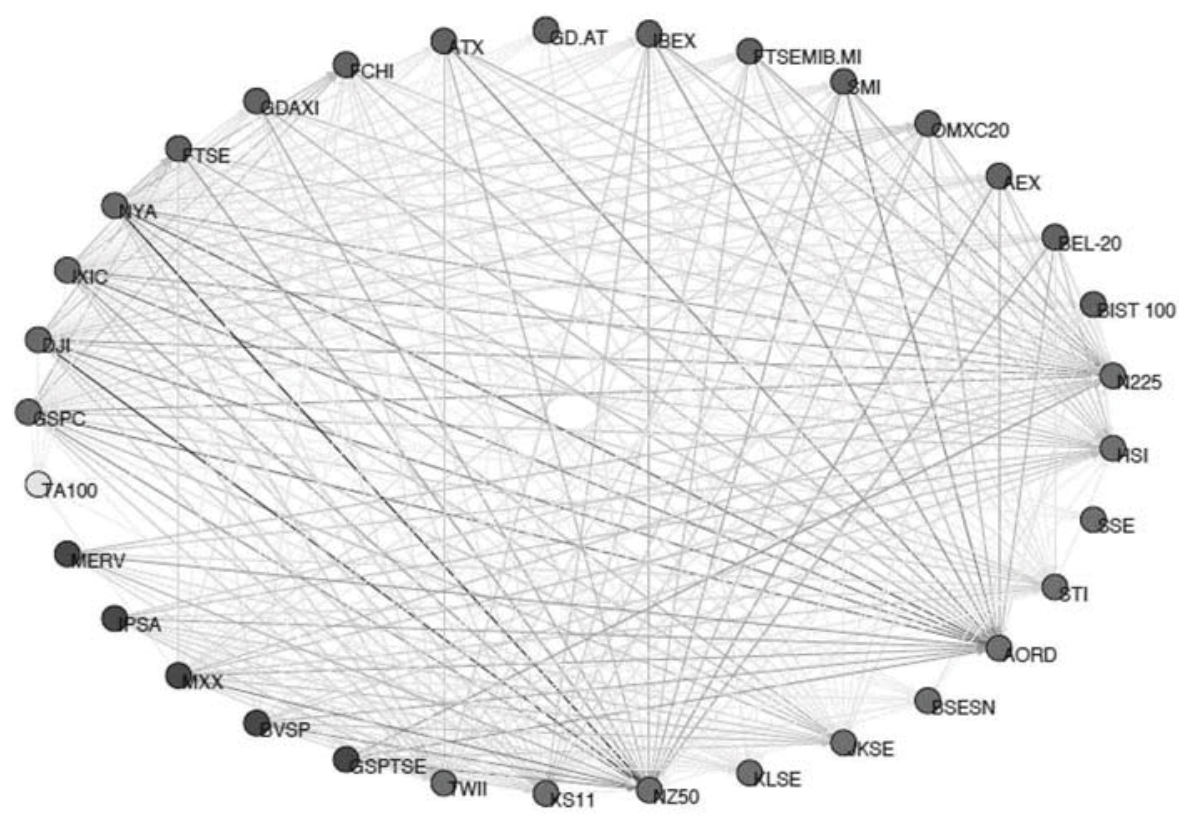

(b) Top $25 \%$ edges

Figure 3. The Granger Networks of the 33 Indices Calculated From the Whole Period With Edges of Top 5 Percent and 25 Percent, Respectively 
(Indonesia) have the highest in-degree from the United States, Americas, and European indices. The other Asian indices are little influenced with no inbound edges among the top 5 percent edges as shown in Figure 3(a) and only weak inbound edges among the top 25 percent edges as shown in Figure 3(b). Notably, the SSE (Shanghai, China), the index of the Shanghai Stock Exchange, is almost independent from other indices with no edges among the top 5 percent edges. This result reconfirms the previous findings that China's stock market, even as an important global economy, is rather isolated. In other words, the internal factors are more influential than the external factors for SSE. The AT100 (Israel, Middle East) has no edges among the top 5 percent and has inbound edges from U.S. indices among top 25 percent, indicating that AT100 is only mainly influenced by the U.S. markets.

\section{Sliding Windows}

To investigate how influences among indices evolve in our study period between April 1, 2007, and June 11, 2015, sliding window approach is adopted. A window size of $L=50$ trading dates, that is, two trading months, is selected. For each sliding window at time $t$, we cover a period in $[t-L+1, t]$. This results in 2,307 windows. Granger causality for all indices and the average over all windows is analyzed. We get a set of average values of $\left\langle d_{i}^{\text {in }}\right\rangle,\left\langle d_{i}^{\text {out }}\right\rangle,\left\langle d_{i}^{\text {total }}\right\rangle$, and $\left\langle I F_{i}\right\rangle$ for each index. In Table 3, results of descending order according to the influence factor are presented. U.S. indices are at the top of all indices with largest $I F_{i}$ followed by other American indices. The European indices are in the middle leading the Asian indices, which have negative $I F_{i}$ indicating that Asian indices are mainly influenced by the rest indices while contributing less influences to the rest indices. In Figures 4(a) and 4(b), we present the averaged Granger causality networks with top 5 percent edges and 25 percent edges. Comparing with Figures 3(a) and 3(b) directly computed from the whole period, the networks are similar indicating that the causal patterns are stable. The United States is a key player, and Asian indices like N255 (Japan), HSI (Hong Kong), AORD (Australia), NZ50 (New Zealand), and KS11 (Korea) have the highest in-degrees and are influenced by U.S. and European indices. It is very interesting to find that N255 is influenced by both U.S. and European indices, whereas AORD is influenced by all U.S., European, and American indices, but KS11, NZ50, and KLSE are influenced only by U.S. indices. This gives new insights to the global indices dynamics that have potential implication for global macro hedge funds.

Because the Granger causality networks are directed, it is interesting to apply the PageRank algorithm from the graph theory to study the influences of each index. First introduced to rank web pages in the design of web search engine, PageRank is very efficient to quantify the importance of vertices [59]. To carry the PageRank algorithm, at first, for a vertex $v_{i}$, we initialize it with a probability $P_{i}(0)=1 / N$, where $N$ is the number of 
Table 3. $\left\langle d_{i}^{\text {in }}\right\rangle,\left\langle d_{i}^{\text {out }}\right\rangle,\left\langle d_{i}^{\text {total }}\right\rangle$, and $\left\langle I F_{i}\right\rangle$ for Each Index of the Granger Causality Network in the Descending Order of $I F_{i}$ Averaged Over All Sliding Windows.

\begin{tabular}{|c|c|c|c|c|c|c|}
\hline Tick & Country & Region & $\left\langle d_{i}^{i n}\right\rangle$ & $\left\langle d_{i}^{\text {out }}\right\rangle$ & $\left\langle d_{i}^{\text {total }}\right\rangle$ & $\left\langle I F_{i}\right\rangle \downarrow$ \\
\hline NYA & US & American & 7.5611 & 18.4207 & 25.9818 & 0.5174 \\
\hline GSPC & US & American & 7.5629 & 18.0580 & 25.6209 & 0.5128 \\
\hline DJI & US & American & 7.7325 & 17.6820 & 25.4145 & 0.5007 \\
\hline IXIC & US & American & 7.3472 & 18.3074 & 25.6546 & 0.4902 \\
\hline$M X X$ & Mexico & Americas & 9.5195 & 12.7418 & 22.2613 & 0.4308 \\
\hline GSPTSE & Canada & Americas & 8.9539 & 12.4544 & 21.4083 & 0.3963 \\
\hline BVSP & Brazil & Americas & 9.5837 & 12.5961 & 22.1798 & 0.3774 \\
\hline MERV & Argentina & Americas & 9.3180 & 11.9105 & 21.2285 & 0.3697 \\
\hline IPSA & Chile & Americas & 9.1678 & 8.6355 & 17.8034 & 0.3065 \\
\hline FTSEMIB & Italy & Europe & 9.1497 & 11.8959 & 21.0456 & 0.2730 \\
\hline GDAXI & Germany & Europe & 8.6413 & 11.9823 & 20.6236 & 0.2573 \\
\hline IBEX & Spain & Europe & 10.3082 & 11.6470 & 21.9553 & 0.2207 \\
\hline FTSE & UK & Europe & 10.0341 & 10.6067 & 20.6408 & 0.2186 \\
\hline $\mathrm{FCHI}$ & France & Europe & 9.7467 & 12.2285 & 21.9752 & 0.2172 \\
\hline ATX & Austria & Europe & 9.8539 & 12.3849 & 22.2387 & 0.1948 \\
\hline AEX & Netherlands & Europe & 9.7489 & 9.4066 & 19.1554 & 0.1923 \\
\hline BEL-20 & Belgium & Europe & 20.1630 & 7.0651 & 27.2281 & 0.1879 \\
\hline SMI & Switzerland & Europe & 17.3570 & 7.4978 & 24.8547 & 0.1362 \\
\hline OMXC20 & Denmark & Europe & 9.7099 & 7.2294 & 16.9393 & 0.0970 \\
\hline GD.AT & Greece & Europe & 16.2644 & 7.9712 & 24.2356 & 0.0687 \\
\hline BIST 100 & Turkey & Europe & 20.9451 & 7.6980 & 28.6430 & 0.0355 \\
\hline SSE & China & Asia & 11.4504 & 9.1236 & 20.5740 & -0.0245 \\
\hline BSESN & India & Asia & 14.5673 & 6.9854 & 21.5527 & -0.0672 \\
\hline TA100 & Israel & $\begin{array}{l}\text { Middle } \\
\text { East }\end{array}$ & 15.6050 & 7.5664 & 23.1714 & -0.0830 \\
\hline KLSE & Malaysia & Asia & 17.8609 & 8.2427 & 26.1036 & -0.2813 \\
\hline JKSE & Indonesia & Asia & 17.8503 & 7.4889 & 25.3392 & -0.3166 \\
\hline STI & Singapore & Asia & 16.7086 & 7.2042 & 23.9128 & -0.3404 \\
\hline NZ50 & $\begin{array}{l}\text { New } \\
\text { Zealand }\end{array}$ & Asia & 7.9043 & 14.5323 & 22.4367 & -0.3555 \\
\hline TWII & Taiwan & Asia & 7.8773 & 14.8330 & 22.7104 & -0.3749 \\
\hline $\mathrm{HSI}$ & Hong Kong & Asia & 7.7600 & 15.4663 & 23.2263 & -0.3948 \\
\hline KS II & Korea & Asia & 8.1554 & 12.1461 & 20.3016 & -0.4051 \\
\hline AORD & Australian & Asia & 7.3313 & 12.5239 & 19.8552 & -0.4911 \\
\hline N225 & Japan & Asia & 10.9486 & 8.1554 & 19.1041 & -0.4993 \\
\hline
\end{tabular}

vertices. At iteration $t$, we update the probability according to the outbound edges of each vertex as

$$
P_{i}(t+1)=\frac{1-d}{N}+d \sum_{\mathrm{j} \rightarrow \mathrm{i}} \frac{P_{j}(t)}{L_{j}},
$$

where $d$ is the damping factor to mimic the random behavior of a browser, and $L_{j}$ is the total out-degree of $v_{j}$, we require a directed edge $\vec{e}_{i j}$ to exist between $v_{i}$ and $v_{j}$. By repeating this updating for enough time, we can get 


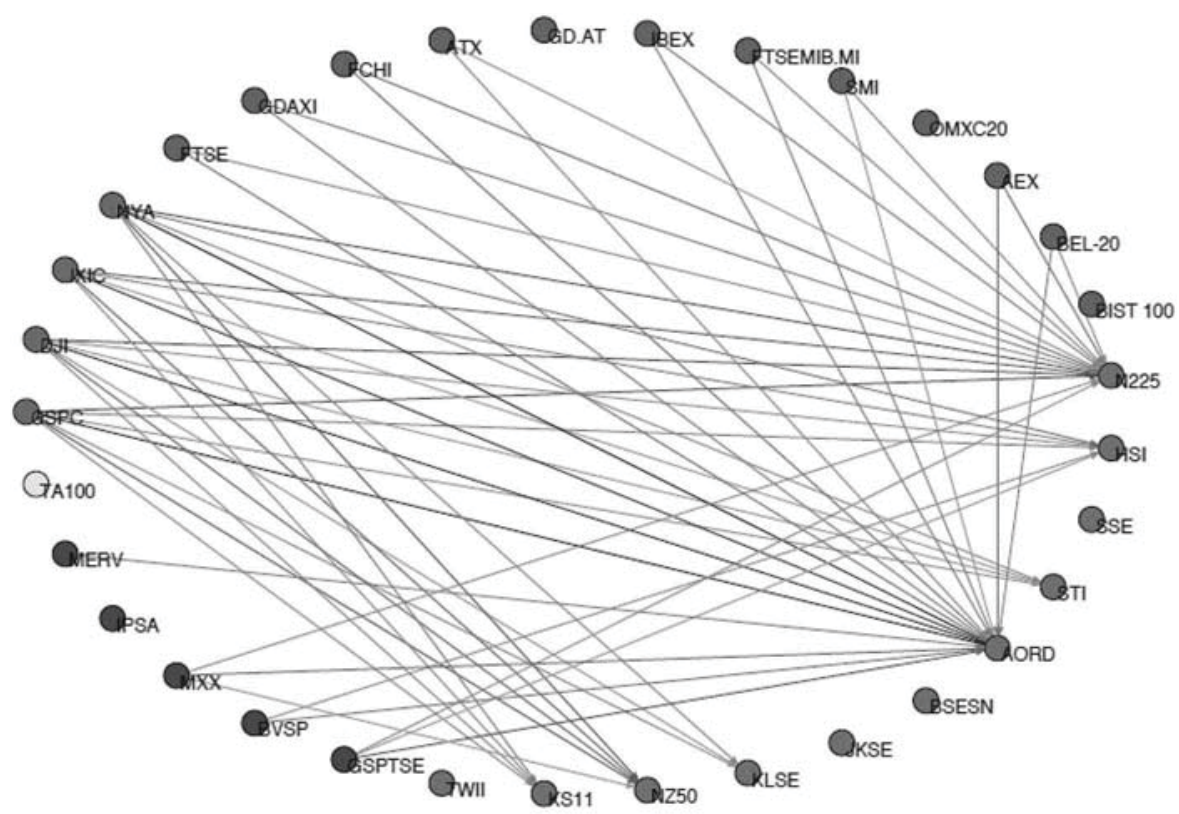

(a) Top 5\% edges

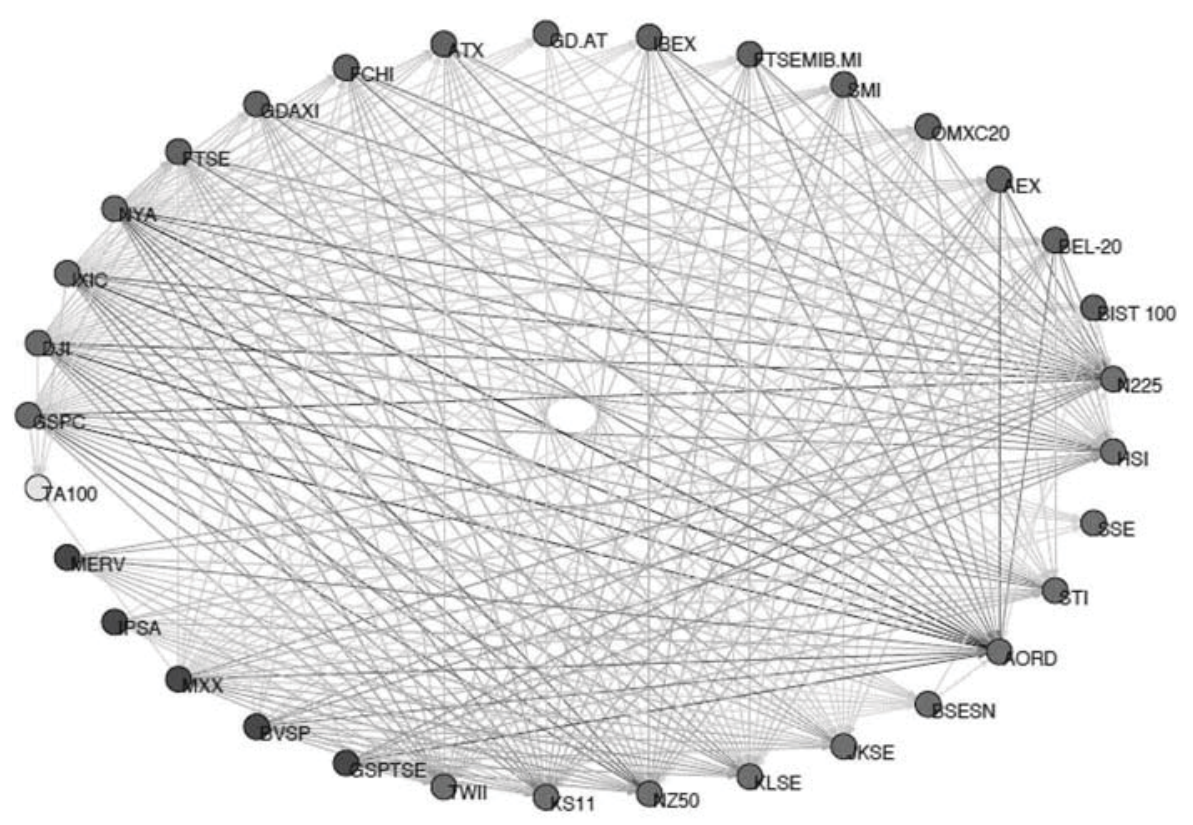

(b) Top $25 \%$ edges

Figure 4. The Granger Networks of 33 Indices Averaged Over All Sliding Windows With Edges of Top 5 Percent and 25 Percent, Respectively 
the PageRank order of all vertices. For our case, on the contrary, the influencing vertex has more out degrees and less in degrees, whereas the influenced vertex has more in degrees and less out degrees. The influencing vertex is more important than the influenced vertex in the network. Therefore, the original version of PageRank is not suitable here. We used the alternative PageRank centrality to calculate the importance of each vertex. Similar to the original algorithm, using the data of the 33 indices, we apply the PageRank centrality $[9,51,53,59]$ to study the influence distribution among the markets. As an alternative eigenvector centrality, the PageRank centrality values indicate the importance with which we further rank the indices of the network. In Table 4, we present the rankings of all indices in the descending order of PageRank centrality values compared with the averaged influence factor $\left\langle I F_{i}\right\rangle$. We find an astonishing similarity of rankings from this PageRank centrality approach with the results based on averaged influence factor $\left\langle I F_{i}\right\rangle$ as shown in Table 3. In the PageRank table, U.S. indices again dominate the top positions followed with Americas indices and Asian indices.

\section{Lead/Lag Network}

As we discussed in the previous section, by conducting a Granger causality test for index $I_{i}$ and $I_{j}$, we can establish a directed edge $\vec{e}_{i j}$ from $I_{i}$ to $I_{j}$ if the test tells $I_{i}$ Granger causes $I_{j}$. In this section, we study the importance of the effect of the lead/lag between stocks. The Granger causality from $I_{i}$ to $I_{j}$ indicates if we include the past information of $I_{i}$, we can improve the prediction of $I_{j}$ in a linear model manner. However, this does not necessarily reveal the lead/lag relationship between the two stocks. The correlation coefficients indicate how the stocks co-move with one another in a synchronous way. However, we have evidence that the markets are not perfectly efficient where impacts or signals spread over the market in an asynchronous way. When market participants absorb, respond, and adjust with different speeds, as a result, some might move ahead of others with different lead/lag time gaps. The lead/lag effect, as an evidence against the Efficient Market Hypothesis, has great potential implications for investors and traders. Some recent literatures study the lagged correlations to explore the lead/lag effect. In Curme et al. [23], a lagged correlation network is constructed for the stock market with discussion of the topological properties, and the result reveals the growth in efficiency and instability. In this study, the intraday price data are used at time horizons from five minutes up to 130 minutes. In another study, the daily price data are used for NYSE market [30], in which the author points that the lead/lag effect will be much smaller in daily data but may not be negligible nonetheless. Our following study based on the daily price data of all 33 indices around the world provides additional evidence for this argument by revealing positive lead/lag effects among the major international stock market indices. Time-dependent correlation (lagged correlation) is investigated for 
Table 4. PageRank Centrality Values and Averaged Influence Factor $\left\langle I F_{i}\right\rangle$ of All 33 Indices Ranked in Descending Order of PageRank.

\begin{tabular}{|c|c|c|c|c|}
\hline Tick & Country & Region & $\left\langle I F_{i}\right\rangle$ & PageRank \\
\hline GSPC & US & American & 0.5128 & 0.0791 \\
\hline NYA & US & American & 0.5174 & 0.0787 \\
\hline DJI & US & American & 0.5007 & 0.0773 \\
\hline IXIC & US & American & 0.4902 & 0.0749 \\
\hline MXX & Mexico & Americas & 0.4308 & 0.0641 \\
\hline BVSP & Brazil & Americas & 0.3774 & 0.0477 \\
\hline GSPTSE & Canada & Americas & 0.3963 & 0.0365 \\
\hline MERV & Argentina & Americas & 0.3697 & 0.0267 \\
\hline IPSA & Chile & Americas & 0.3065 & 0.0258 \\
\hline $\mathrm{FCHI}$ & France & Europe & 0.2172 & 0.0250 \\
\hline FTSE & UK & Europe & 0.2186 & 0.0239 \\
\hline AEX & Netherlands & Europe & 0.1923 & 0.0239 \\
\hline GDAXI & Germany & Europe & 0.2573 & 0.0236 \\
\hline BEL-20 & Belgium & Europe & 0.1879 & 0.0234 \\
\hline $\begin{array}{l}\text { FTSEMIB. } \\
\text { MI }\end{array}$ & Italy & Europe & 0.2730 & 0.0233 \\
\hline IBEX & Spain & Europe & 0.2207 & 0.0232 \\
\hline SMI & Switzerland & Europe & 0.1362 & 0.0231 \\
\hline ATX & Austria & Europe & 0.1948 & 0.0229 \\
\hline OMXC20 & Denmark & Europe & 0.0970 & 0.0219 \\
\hline BIST 100 & Turkey & Europe & 0.0355 & 0.0207 \\
\hline GD.AT & Greece & Europe & 0.0687 & 0.0200 \\
\hline BSESN & India & Asia & -0.0672 & 0.0188 \\
\hline JKSE & Indonesia & Asia & -0.3166 & 0.0180 \\
\hline TA 100 & Israel & $\begin{array}{l}\text { Middle } \\
\text { East }\end{array}$ & -0.0830 & 0.0179 \\
\hline STI & Singapore & Asia & -0.3404 & 0.0179 \\
\hline N225 & Japan & Asia & -0.4993 & 0.0177 \\
\hline $\mathrm{HSI}$ & Hong Kong & Asia & -0.3948 & 0.0177 \\
\hline SSE & China & Asia & -0.0245 & 0.0177 \\
\hline AORD & Australian & Asia & -0.4911 & 0.0177 \\
\hline KLSE & Malaysia & Asia & -0.2813 & 0.0177 \\
\hline NZ50 & $\begin{array}{l}\text { New } \\
\text { Zealand }\end{array}$ & Asia & -0.3555 & 0.0177 \\
\hline KS 11 & Korea & Asia & -0.4051 & 0.0177 \\
\hline TWII & Taiwan & Asia & -0.3749 & 0.0177 \\
\hline
\end{tabular}

Chinese stock market in Geo, Zeng, and Cai [32] showing that a few large companies are leading the market. It is worth noting that the co-integration between time series provides information on how two series are related, but this provides no information of lead/lad effect. Using an approach by studying the co-integration relationships among global market, co-integration directed networks are studied in Yang et al. [76]. This is different from our following lagged correlation approach. 
Consider two returns of indices $I_{i}$ and $I_{j}$, for a certain period; the lagged correlation coefficient or cross-correlation coefficient,

$$
\rho_{i j}^{t}(\tau)=\frac{Y_{i}(t) Y_{j}(t+\tau)-Y_{i}(t) Y_{j}(t+\tau)}{\sqrt{\left(Y_{i}^{2}(t)-Y_{i}(t)^{2}\right)\left(Y_{j}^{2}(t)-Y_{j}(t+\tau)^{2}\right)}},
$$

indicates how the index $I_{i}$ is correlated to index $I_{j}$ with a lag of $\tau$, where $<Y_{i}(t) \geq$ $1 / L \sum_{t} Y_{i}(t)$ is the average of returns for $I_{i}$ in a period with a length of $L$. Because the introduction of $\tau$, we see that $\rho_{i j}^{t}(\tau) \neq \rho_{j i}^{t}(\tau)$, so the lagged correlation matrix of all indices is asymmetric. This lagged correlation coefficient also ranges in the interval of $[-1,1]$, that is, $-1 \leq \rho_{i j}^{t}(\tau) \leq 1$. If $\rho_{i j}^{t}(\tau)>0$, then $I_{i}$ is positively correlated with $I_{j}$ in a lead of $\tau$. In other words, $I_{j}$ is afollower of $I_{i}$. In a less strict but safe way, we say $I_{i}$ influences $I_{j}$ to move in the same direction as $I_{i}$ does. For the case of $\rho_{i j}^{t}(\tau)<0$, a negative value of $\rho_{i j}^{t}(\tau)$ indicates $I_{i}$ has an influence on $I_{j}$ to move in a counter direction with a lead of $\tau$. If $\rho_{i j}^{t}(\tau) \neq 0$, we can use this information to extract the lead/lag structure among all pairs in the set of indices. To simplify the lead/lag network, we compare the correlation coefficients on the directed edges of $\vec{e}_{i j}$ and $\vec{e}_{j i}$,

$$
\vec{e}_{i j}= \begin{cases}\rho_{i j}^{t}(\tau) \text { if } & \left|\rho_{i j}^{t}(\tau)\right|>\left|\rho_{j i}^{t}(\tau)\right|, \\ 0 & \text { otherwise, }\end{cases}
$$

in other words, we only keep the lead/lag effect with larger absolute correlation in the two directed edges of $\vec{e}_{i j}$ and $\vec{e}_{j i}$. In this way, only one edge is kept to link $I_{i}$ and $I_{j}$. This approach greatly simplifies the network by filtering out half of the total edges. We consider $\tau$ ranges up to 20 days. In Figure 5, we plot the average lagged correlation coefficient $\left\langle\rho_{i j}\right\rangle$ and standard deviation $\sigma_{i j}$ for each lag value, we see that when $\tau=1$, both values are significantly different from the mean values. This implicates the lead/lag effect is relatively significant at $\tau=1$ and fades out with the increasing lag length. This actually agrees with some macro economy observations that the impact of global indices spread around the world and the time window to react to external influence is very short. If it is a daily basis, the effective lead/lag time would be no longer than one day. This empirical finding suggests that there is a lead/lag effect among indices even if the corresponding correlation is smaller than 0.1. Using the filtering approach (Equation 6), we extract the top 5 percent and 25 percent edges and present the lead/lag networks in Figures 6(a) and 6(b), respectively. As shown in the figures, we find that there is a great similarity of top edges in the lead/lag networks with the Granger networks of the whole period (Figure 3) and the average of all sliding windows (Figure 4), especially for the case of top 5 percent networks. Again, we confirmed that U.S. indices are leading indices and Asian indices of N255 (Japan), HSI (Hong Kong), AORD (Australia), NZ250 (New Zealand), and TWII (Taiwan) are lagged mainly to U.S. indices and some European indices. To evaluate the leading effects of all indices, we apply the PageRank centrality algorithm to the lead/lag networks with a lag of $\tau=1$; we rank the indices in a 

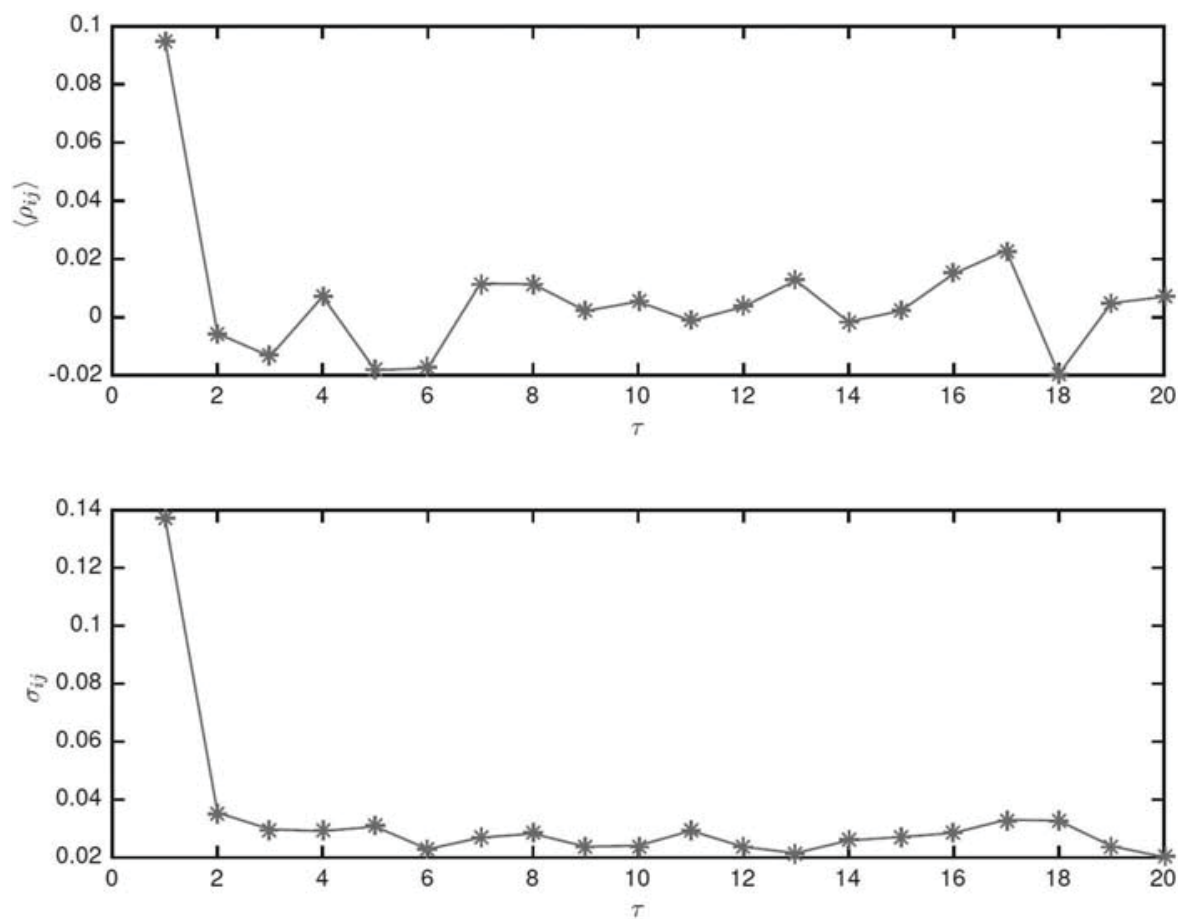

Figure 5. The Average Correlation $\left\langle\rho_{i j}\right\rangle$ and standard Deviation $\sigma_{i j}$ of Lead/Lag Network of 33 Indices Over the Whole Study Period for Different Lag Lengths From 1 to 20

descending order according to the PageRank centrality values and present the result in Table 5. We see that the indices rankings based on lead/lag networks are similar to the results based on the ranking of influence factor values of Granger causality networks of whole period (Table 1) and averaged over all sliding windows (Table 3). The ranking is also similar to the rankings of PageRank centrality values of Granger causality networks (Table 4). In the PageRank ranking of lead/lag networks, the U.S. indices again top the leading positions with exception of MXX (Mexico), ranked in the third place. Most European indices are in the middle part, followed by the Asian indices. This finding indicates that Granger causality and the lead/lag effect from the lagged correlation approach reveal the same pattern of the dynamics of global indices.

\section{Conclusion}

Financial network analysis is an innovative method to quantitatively study the dynamics of financial markets. As a Financial Big Data approach, it provides new tools to analyze and visualize the interrelationships of assets. Different from the undirected financial network analysis, which omits the causal or influence direction, the directed financial network analysis can 


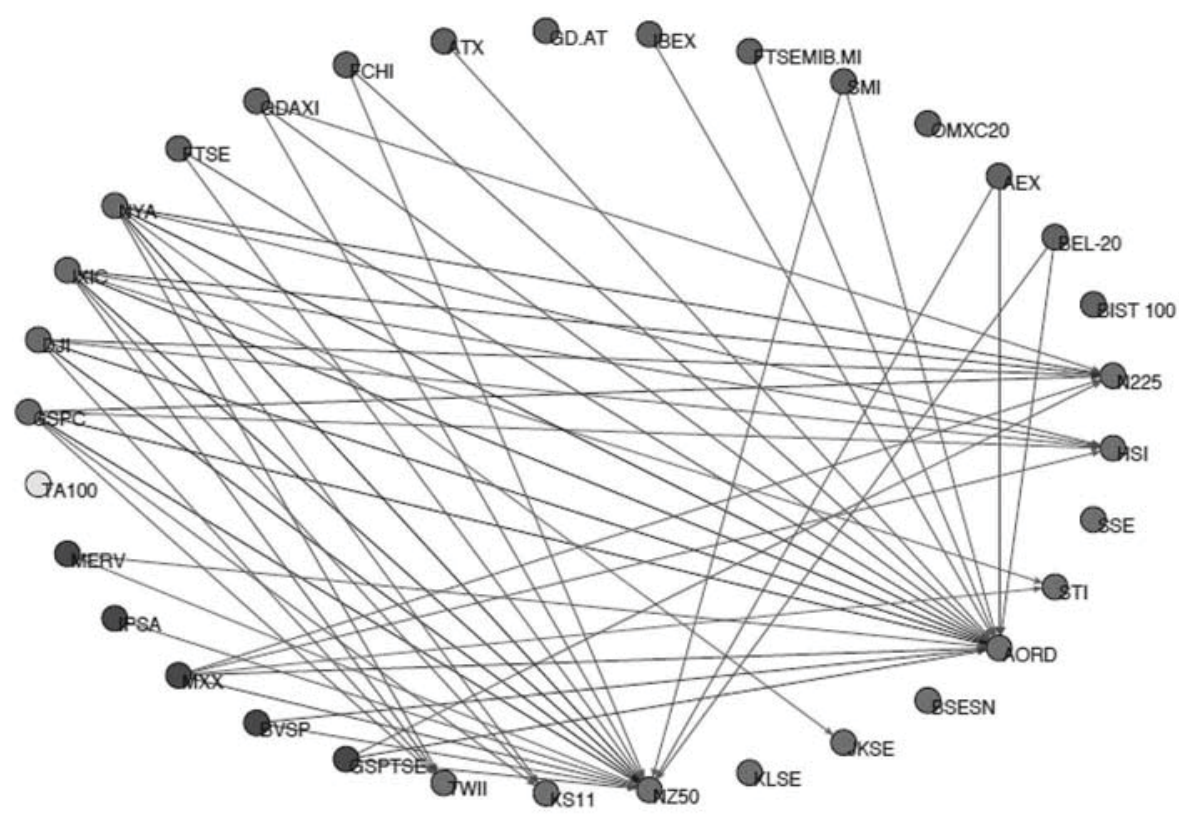

(a) Top $5 \%$ edges

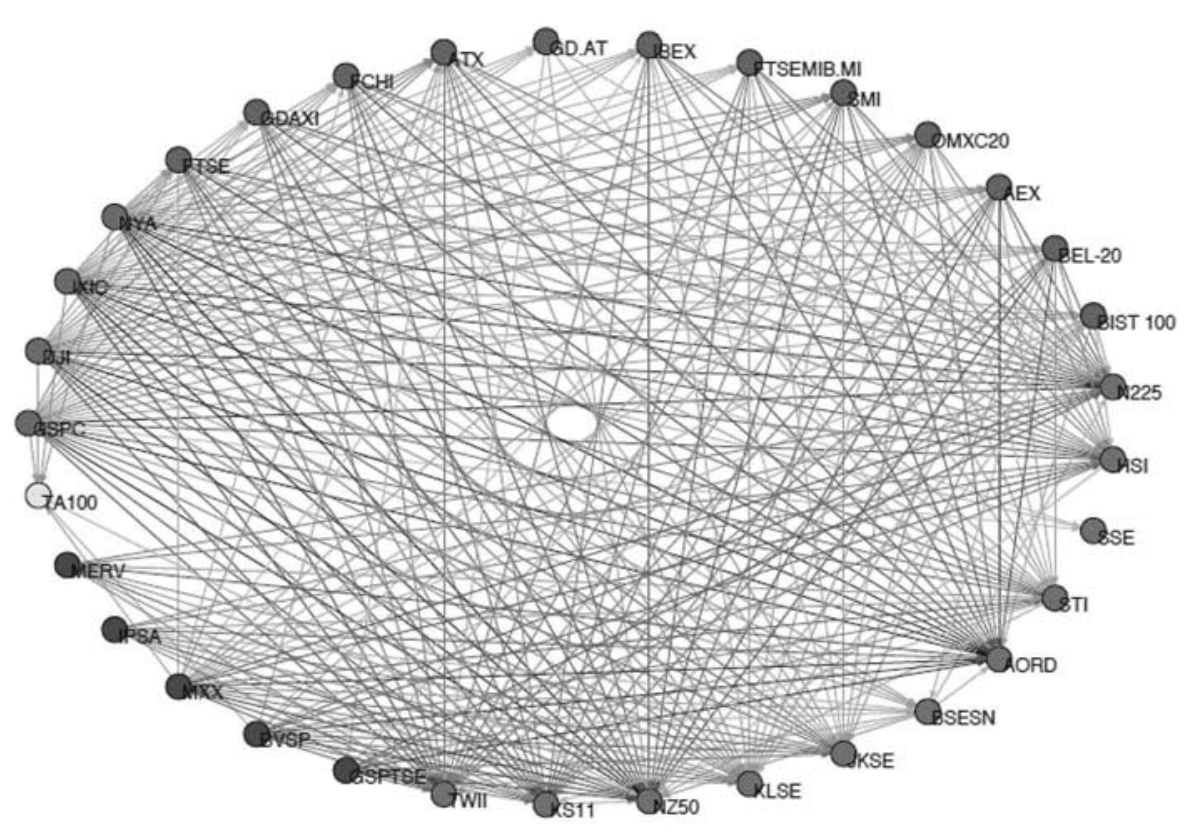

(b) Top 25\% edges

Figure 6. The Lead/Lag Networks $(\tau=1)$ of 33 Indices of the Whole Study Period With Edges of Top 5 Percent (a) and 25 Percent (b), Respectively 
Table 5. PageRank Centrality Values in Descending Order Calculated for All Indices of the Top 5 Percent Edges of Lead/Lag $(\tau=1)$ Network for All 33 Indices.

\begin{tabular}{|c|c|c|c|}
\hline Tick & Country & Region & PageRank $\downarrow$ \\
\hline NYA & US & American & 0.0701 \\
\hline IXIC & US & American & 0.0596 \\
\hline GSPC & US & American & 0.0484 \\
\hline$M X X$ & Mexico & Americas & 0.0455 \\
\hline DJI & US & American & 0.0411 \\
\hline GSPTSE & Canada & Americas & 0.0304 \\
\hline GDAXI & Germany & Europe & 0.0301 \\
\hline BVSP & Brazil & Americas & 0.0278 \\
\hline AEX & Netherlands & Europe & 0.0276 \\
\hline FTSE & UK & Europe & 0.0276 \\
\hline BEL-20 & Belgium & Europe & 0.0275 \\
\hline $\mathrm{FCHI}$ & France & Europe & 0.0275 \\
\hline SMI & Switzerland & Europe & 0.0275 \\
\hline MERV & Argentina & Americas & 0.0274 \\
\hline IPSA & Chile & Americas & 0.0264 \\
\hline $\begin{array}{l}\text { FTSEMIB. } \\
\text { MI }\end{array}$ & Italy & Europe & 0.0262 \\
\hline IBEX & Spain & Europe & 0.0262 \\
\hline ATX & Austria & Europe & 0.0262 \\
\hline GD.AT & Greece & Europe & 0.0251 \\
\hline OMXC20 & Denmark & Europe & 0.0251 \\
\hline BIST 100 & Turkey & Europe & 0.0251 \\
\hline N225 & Japan & Asia & 0.0251 \\
\hline $\mathrm{HSI}$ & Hong Kong & Asia & 0.0251 \\
\hline SSE & China & Asia & 0.0251 \\
\hline STI & Singapore & Asia & 0.0251 \\
\hline AORD & Australian & Asia & 0.0251 \\
\hline BSESN & India & Asia & 0.0251 \\
\hline JKSE & Indonesia & Asia & 0.0251 \\
\hline KLSE & Malaysia & Asia & 0.0251 \\
\hline NZ50 & $\begin{array}{l}\text { New } \\
\text { Zealand }\end{array}$ & Asia & 0.0251 \\
\hline KS 11 & Korea & Asia & 0.0251 \\
\hline TWII & Taiwan & Asia & 0.0251 \\
\hline TA100 & Israel & $\begin{array}{l}\text { Middle } \\
\text { East }\end{array}$ & 0.0251 \\
\hline
\end{tabular}

reveal how the information or influence is spreading among the assets. The directed financial network analysis is an essential supplement to the undirected approaches. In this study, we discussed the Granger causality network and time lead/lag network built using global indices. Our approach can be applied to stock markets, future markets, and so on. The two assets in the lead/lag pair can be from the same market or two markets, such a stock market and a future market. To take advantages of the findings of the 
causality networks or lead/lag networks in designing of trading strategies, one can use the leading asset as an indicator for the lagged asset. The lead/ lag relationship between assets and financial markets is important for the studies of trading strategies design and high-frequency analysis [12, 21, 39, 44]. For lead/lag correlated pair assets, when the leading reaches the local maximum, we long the lagged, or when the leading reaches the local minimum, we short the lagged. First, we use the Granger and lead/lag approaches to identify the lead/lag pairs and their time lags, then we apply the trading strategies and monitor the lags. In our research, both approaches reveal similar ranking of influences for the 33 indices of global major stock markets. Our work contributes to the literature in multiple folds. First, we provide a systematical study of the global markets by modeling as directed financial networks both in the Granger causality network and the lead/lag network. Second, the topological properties of the directed networks are discussed, revealing the influence relationships among the global markets. Third, through the directed edge information, we reveal that the U.S. stock markets are dominating the networks with the highest influences, whereas the Asian stock markets are the most influenced markets by other markets. Forth, we verify the influence rankings using the PageRank centrality approach. Finally, we observed a lead/lag effect in the global markets through directed networks. These findings bring new evidence and implications of global trading strategy design as well as global market risk monitoring. However, this work still needs further efforts to overcome the limitations. More price data in higher frequencies could be used to explore the market behaviors in small time scales; other causality tests can be used to build directed networks. Also, we should be aware that the causality revealed from the Granger causality tests is valid in the scope of the Granger causality test. We shall not take it too far to conclude that there is specific causality between concerned series, as all causalities have been embedded in the final test results: This is the same way that all market information has been reflected in the final prices. The causality indicates that the predictive information is embedded in one series for another series. Although the limitations of Granger causality, the observed causality can be informative for the dynamics analysis.

It is worth mentioning that in designing trading strategy in the global markets, the asynchronous market opening and closing need to be considered, for the different trading periods of global markets in different time zones. Moreover, it would be both exciting and rewarding to explore the possibilities of combining financial network analysis with other big data approaches such as sentiment analysis [1, 66]. As further research, one might study how the directed global financial network changes with the sentiment reflected from other data sources like investor activities or social media. With the availability of Financial Big Data and network analysis theories and tools, by building the directed networks of global financial markets, we can not only further visualize the networks but also monitor the evolvement of the topological structures. Because global economies are becoming increasingly interconnected, it is crucial for 
governments, regulators, and policymakers to closely watch the networks of global stock markets in hopes of avoiding systemic failures like financial crises.

\section{Acknowledgments}

We gratefully acknowledge all editors and anonymous reviewers for their valuable comments and help, which significantly improved the quality of this work.

\section{Supplemental data}

Supplemental data for this article can be accessed on the publisher's website.

\section{ORCID}

Yong Tang (i) http://orcid.org/0000-0002-5036-4350

\section{REFERENCES}

1. Baker, M.; Wurgler, J.; and Yuan, Y. Global, local, and contagious investor sentiment. Journal of Financial Economics, 104, 2 (2012), 272-287.

2. Barabási, A.-L.; and Albert, R. Emergence of scaling in random networks. Science, 286, 5439 (1999), 509-512.

3. Battiston, S.; and Catanzaro, M. Statistical properties of corporate board and director networks. The European Physical Journal B - Condensed Matter and Complex Systems, 38, 2 (2004), 345-352.

4. Battiston, S.; Farmer, J.D.; Flache, A.; Garlaschelli, D.; Haldane, A.G.; Heesterbeek, H.; Hommes, C.; Jaeger, C.; May, R.; and Scheffer, M.

Complexity theory and financial regulation. Science, 351, 6275 (2016), 818-819.

5. De Benedictis, L.; and Tajoli, L. The World Trade Network. The World Economy, 34, 8 (2011), 1417-1454.

6. Bertero, E.; and Mayer, C. Structure and performance: Global interdependence of stock markets around the crash of October 1987. European Economic Review, 34, 6 (1990), 1155-1180.

7. Billio, M.; Getmansky, M.; Lo, A.W.; and Pelizzon, L. Econometric measures of connectedness and systemic risk in the finance and insurance sectors. Journal of Financial Economics, 104, 3 (2012), 535-559.

8. Boginski, V.; Butenko, S.; and Pardalos, P.M. Statistical analysis of financial networks. Computational Statistics \& Data Analysis, 48, 2 (2005), 431-443.

9. Boldi, P.; Santini, M.; and Vigna, S. PageRank: functional dependencies. ACM Transactions on Information Systems, 27, 4 (2009), 19. 
10. Boss, M.; Elsinger, H.; Summer, M.; and Thurner, S. Network topology of the interbank market. Quantitative Finance, 4, 6 (2004), 677-684.

11. Brida, J.G.; and Risso, W.A. Hierarchical structure of the German stock market. Expert Systems with Applications, 37, 5 (2010), 3846-3852.

12. Brooks, C.; Rew, A.G.; and Ritson, S. A trading strategy based on the lead-lag relationship between the spot index and futures contract for the FTSE 100. International Journal of Forecasting, 17, 1 (2001), 31-44.

13. Caldarelli, G.; Battiston, S.; Garlaschelli, D.; and Catanzaro, M.

Emergence of complexity in financial networks. In E. Ben-Naim, H.

Frauenfelder, and Z. Toroczkai (eds). Complex Networks. Berlin Heidelberg: Springer, 2004, pp. 399-423.

14. Caraiani, P. Characterizing emerging European stock markets through complex networks: From local properties to self-similar characteristics.

Physica A: Statistical Mechanics and its Applications, 391, 13 (2012), 3629-3637.

15. Caraiani, P. Using complex networks to characterize International business cycles. PLoS ONE, 8, 3 (2013), e58109.

16. Cavusoglu, H.; Mishra, B.; and Raghunathan, S. The effect of internet security breach announcements on market value: capital market reactions for breached firms and internet security developers. International Journal of Electronic Commerce, 9, 1 (2004), 70-104.

17. Chen, K.; Luo, P.; Sun, B.; and Wang, H. Which stocks are profitable? A network method to investigate the effects of network structure on stock returns. Physica A: Statistical Mechanics and its Applications, 436(2015), 224-235. 18. Chen, T. Do Investors Herd in Global Stock Markets? Journal of Behavioral Finance, 14, 3 (2013), 230-239.

19. Chiang, T.C.; and Zheng, D. An empirical analysis of herd behavior in global stock markets. Journal of Banking \& Finance, 34, 8 (2010), 1911-1921.

20. Clemons, E.K.; and Weber, B.W. Adverse self-selection and the changing competitive balance between stock exchanges and off-exchange trading venues. International Journal of Electronic Commerce, 1, 3 (1997), 21-41.

21. Copeland, M.; and Copeland, T. Leads, lags, and trading in global markets. Financial Analysts Journal, 54, 4 (1998), 70-80.

22. Çukur, S.; Eryiğit, M.; and Eryiğit, R. Cross correlations in an emerging market financial data. Physica A: Statistical Mechanics and its Applications, 376, (2007), 555-564.

23. Curme, C.; Tumminello, M.; Mantegna, R.N.; Stanley, H.E.; and Kenett, D.Y. Emergence of statistically validated financial intraday lead-lag relationships. Quantitative Finance, 15, 8 (2015), 1375-1386.

24. Engle, R.F.; and Granger, C.W.J. Co-integration and error correction: representation, estimation, and testing. Econometrica, 55, 2 (1987), 251-276. 25. Eryiğit, M.; and Eryiğit, R. Network structure of cross-correlations among the world market indices. Physica A: Statistical Mechanics and its Applications, 388, 17 (2009), 3551-3562.

26. Fan, M.; Stallaert, J.; and Whinston, A.B. The design and development of a financial cybermarket with a bundle trading mechanism. International Journal of Electronic Commerce, 4, 1 (1999), 5-22. 
27. Farmer, J.D.; Gallegati, M.; Hommes, C.; Kirman, A.; Ormerod, P.; Cincotti, S.; Sanchez, A.; and Helbing, D. A complex systems approach to constructing better models for managing financial markets and the economy. The European Physical Journal Special Topics, 214, 1 (2012), 295-324. 28. Fenn, D.J.; Porter, M.A.; Mucha, P.J.; McDonald, M.; Williams, S.; Johnson, N.F.; and Jones, N.S. Dynamical clustering of exchange rates. Quantitative Finance, 12, 10 (2012), 1493-1520.

29. Ferson, W.E.; and Harvey, C.R. Sources of risk and expected returns in global equity markets. Journal of Banking \& Finance, 18, 4 (1994), 775-803.

30. Fiedor, P. Information-theoretic approach to lead-lag effect on financial markets. The European Physical Journal B, 87, 8 (2014), 168-176.

31. Forbes, K.J.; and Rigobon, R. No contagion, only interdependence: measuring stock market comovements. The Journal of Finance, 57, 5 (2002), 2223-2261.

32. Gao, Y.-C.; Zeng, Y.; and Cai, S.-M. Influence network in the Chinese stock market. Journal of Statistical Mechanics: Theory and Experiment, 2015, 3 (2015), P03017.

33. Glattfelder, J.B. Backbone of complex networks of corporations: the flow of control. In Decoding Complexity: Uncovering Patterns in Economic Networks. Berlin: Springer, 2013, pp. 67-93.

34. Granger, C.W.J. Investigating causal relations by econometric models and cross-spectral methods. Econometrica, 37, 3 (1969), 424-438.

35. Hamao, Y.; Masulis, R.W.; and Ng, V. Correlations in price changes and volatility across international stock markets. The Review of Financial Studies, 3, 2 (1990), 281-307.

36. Hill, S.; and Ready-Campbell, N. Expert stock picker: the wisdom of (experts in) crowds. International Journal of Electronic Commerce, 15, 3 (2011), 73-102.

37. Hjalmarsson, E. Predicting global stock returns. Journal of Financial and Quantitative Analysis, 45, 1 (2010), 49-80.

38. Hou, K.; Karolyi, G.A.; and Kho, B.-C. What factors drive global stock returns? The Review of Financial Studies, 24, 8 (2011), 2527-2574.

39. Huth, N.; and Abergel, F. High frequency lead/lag relationships-

Empirical facts. Journal of Empirical Finance, 26, Supplement C (2014), 41-58. 40. in't Veld, D.; and van Lelyveld, I. Finding the core: Network structure in interbank markets. Journal of Banking E Finance, 49, (2014), 27-40.

41. Iori, G.; Masi, G. De; Precup, O.V.; Gabbi, G.; and Caldarelli, G. A network analysis of the Italian overnight money market. Journal of Economic Dynamics and Control, 32, 1 (2008), 259-278.

42. Jallo, D.; Budai, D.; Boginski, V.; Goldengorin, B.; and Pardalos, P.

Network-based representation of stock market dynamics: An application to American and Swedish stock markets. In B. Goldengorin, V.A. Kalyagin, and P.M. Pardalos (eds.), Models, Algorithms, and Technologies for Network Analysis. New York: Springer, 2013, pp. 93-106.

43. Jang, W.; Lee, J.; and Chang, W. Currency crises and the evolution of foreign exchange market: Evidence from minimum spanning tree. Physica A: Statistical Mechanics and its Applications, 390, 4 (2011), 707-718. 
44. de Jong, F.; and Nijman, T. High frequency analysis of lead-lag relationships between financial markets. Journal of Empirical Finance, 4, 2 (1997), 259-277.

45. Kali, R.; and Reyes, J. The architecture of globalization: a network approach to international economic integration. Journal of International Business Studies, 38, 4 (2007), 595-620.

46. Kannan, K.; Rees, J.; and Sridhar, S. Market reactions to information security breach announcements: An empirical analysis. International Journal of Electronic Commerce, 12, 1 (2007), 69-91.

47. Kenett, D.Y.; Preis, T.; Gur-Gershgoren, G.; and Ben-Jacob, E.

Quantifying meta-correlations in financial markets. Europhysics Letters, 99, 3 (2012), 38001.

48. Kosmidou, K.; Kousenidis, D.; Ladas, A.; and Negkakis, C. Determinants of risk in the banking sector during the European financial crisis. Journal of Financial Stability, 33(2017), 285-296.

49. Li, H.; An, H.; Fang, W.; Wang, Y.; Zhong, W.; and Yan, L. Global energy investment structure from the energy stock market perspective based on a Heterogeneous Complex Network Model. Applied Energy, 194(2017), 648-657. 50. Masih, R.; and Masih, A.M.M. Long and short term dynamic causal transmission amongst international stock markets. Journal of International Money and Finance, 20, 4 (2001), 563-587.

51. Morrison, J.L.; Breitling, R.; Higham, D.J.; and Gilbert, D.R. GeneRank: using search engine technology for the analysis of microarray experiments. BMC Bioinformatics, 6, 1 (2005), 233.

52. Namaki, A.; Shirazi, A.H.; Raei, R.; and Jafari, G.R. Network analysis of a financial market based on genuine correlation and threshold method. Physica A: Statistical Mechanics and its Applications, 390, 21-22 (2011), 3835-3841.

53. Newman, M. Networks: An Introduction. New York: Oxford University Press, 2010.

54. Newman, M.E.J. The structure and function of complex networks. SIAM Review, 45, 2 (2003), 167-256.

55. Nier, E.; Yang, J.; Yorulmazer, T.; and Alentorn, A. Network models and financial stability. Journal of Economic Dynamics and Control, 31, 6 (2007), 2033-2060.

56. Nobi, A.; Lee, S.; Kim, D.H.; and Lee, J.W. Correlation and network topologies in global and local stock indices. Physics Letters A, 378, 34 (2014), 2482-2489.

57. Nobi, A.; Maeng, S.E.; Ha, G.G.; and Lee, J.W. Effects of global financial crisis on network structure in a local stock market. Physica A: Statistical Mechanics and its Applications, 407(2014), 135-143.

58. Ozsoylev, H.N.; Walden, J.; Yavuz, M.D.; and Bildik, R. Investor networks in the stock market. The Review of Financial Studies, 27, 5 (2013), 1323-1366.

59. Page, L.; Brin, S.; Motwani, R.; and Winograd, T. The PageRank citation ranking: Bringing order to the Web. In Proceedings of the 7th International World Wide Web Conference. Brisbane, Australia, 1998, pp. 161-172. 
60. Papana, A.; Kyrtsou, C.; Kugiumtzis, D.; and Diks, C. Financial networks based on Granger causality: A case study. Physica A: Statistical Mechanics and its Applications, 482(2017), 65-73.

61. Peron, T.K.D.; and Rodrigues, F.A. Collective behavior in financial markets. Europhysics Letters, 96, 4 (2011), 48004.

62. Plerou, V.; Gopikrishnan, P.; Rosenow, B.; Amaral, L.A.N.; and Stanley, H. E. Econophysics: Financial time series from a statistical physics point of view. Physica A: Statistical Mechanics and its Applications, 279, 1-4 (2000), 443-456. 63. Podobnik, B.; Horvatic, D.; Petersen, A.M.; and Stanley, H.E. Crosscorrelations between volume change and price change. Proceedings of the National Academy of Sciences, 106, 52 (2009), 22079-22084.

64. Rea, A.; and Rea, W. Visualization of a stock market correlation matrix. Physica A: Statistical Mechanics and its Applications, 400(2014), 109-123.

65. Said, S.E.; and Dickey, D.A. Testing for unit roots in autoregressivemoving average models of unknown order. Biometrika, 71, 3 (1984), 599-607. 66. Schmeling, M. Investor sentiment and stock returns: Some international evidence. Journal of Empirical Finance, 16, 3 (2009), 394-408.

67. Schweitzer, F.; Fagiolo, G.; Sornette, D.; Vega-Redondo, F.; Vespignani, A.; and White, D.R. Economic networks: The new challenges. Science, 325, 5939 (2009), 422-425.

68. da Silva, M.F.; de Area Leão Pereira, É.J.; da Silva Filho, A.M.; de Castro, A.P.N.; Miranda, J.G.V.; and Zebende, G.F. Quantifying cross-correlation between Ibovespa and Brazilian blue-chips: The DCCA approach. Physica A: Statistical Mechanics and its Applications, 424(2015), 124-129.

69. Tu, C. Cointegration-based financial networks study in Chinese stock market. Physica A: Statistical Mechanics and its Applications, 402(2014), 245-254. 70. Vitali, S.; Glattfelder, J.B.; and Battiston, S. The Network of Global Corporate Control. PLoS ONE, 6, 10 (2011), 1-6.

71. Vizgunov, A.; Goldengorin, B.; Kalyagin, V.; Koldanov, A.; Koldanov, P.; and Pardalos, P.M. Network approach for the Russian stock market. Computational Management Science, 11, 1-2 (2014), 45-55.

72. Výrost, T.; Lyócsa, Š.; and Baumöhl, E. Granger causality stock market networks: Temporal proximity and preferential attachment. Physica A: Statistical Mechanics and its Applications, 427(2015), 262-276.

73. Wang, G.-J.; and Xie, C. Correlation structure and dynamics of international real estate securities markets: A network perspective. Physica A: Statistical Mechanics and its Applications, 424(2015), 176-193.

74. Wang, G.-J.; Xie, C.; He, K.; and Stanley, H.E. Extreme risk spillover network: application to financial institutions. Quantitative Finance, 17, 9 (2017), 1417-1433.

75. Watts, D.J.; and Strogatz, S.H. Collective dynamics of "small-world" networks. Nature, 393, 6684 (1998), 440-442.

76. Yang, C.; Chen, Y.; Niu, L.; and Li, Q. Cointegration analysis and influence rank-A network approach to global stock markets. Physica A: Statistical Mechanics and its Applications, 400(2014), 168-185. 
77. Zhang, W.; Li, C.; Ye, Y.; Li, W.; and Ngai, E.W.T. Dynamic business network analysis for correlated stock price movement prediction. Intelligent Systems, IEEE, 30, 2 (2015), 26-33.

78. Zheng, Z.; Podobnik, B.; Feng, L.; and Li, B. Changes in cross-correlations as an indicator for systemic risk. Scientific Reports, 2 (2012), 888.

YONG TANG (tangyong@uestc.edu.cn; corresponding author) is an assistant professor in Department of Computer Software and Theory, School of Computer Science and Engineering, and Department of Management Science and E-Commerce, School of Economics and Management at University of Electronic Science and Technology of China. In the past 10 years, Dr. Tang has been an entrepreneur and founder of several IT companies in China providing enterprise applications and e-commerce solutions. He serves as a consultant for governments and companies. He has participated in research projects of Ministries of Science and Technology and of Education, China, and in industry. He has been engaged in interdisciplinary research in e-commerce, information systems, data science, financial engineering, and artificial intelligence. He has published in China Finance Review International, Economic Modelling, Physica A: Statistical Mechanics and its Applications, Journal of Applied Statistics, and other venues.

JASON JIE XIONG (xiongji@appstate.edu) is an Assistant Professor of Department of Computer Information Systems \& Supply Chain Management, Walker College of Business, Appalachian State University. His research interests include Financial Big Data analysis, IT for Development (IT4D), E-Commerce, and the value of Information Systems. He has published in such journals as China Finance Review International and Physica A: Statistical Mechanics and its Applications, and in the proceedings of such conferences as HICSS, AMCIS, and GlobDev.

YONG LUO (cbi_luoy@aliyun.com) is an assistant professor in Department of Finance, College of Science at Ningbo University of Technology, China, where he also serves as the department head. Dr. Luo has years of industrial practice experience and currently serves as the research director for investment management companies based in Shanghai. His research interests include Financial Big Data, financial engineering, and algorithmic trading. His work appears in such journals as China Finance Review International, Economic Modelling, Physica A: Statistical Mechanics and its Applications, and Journal of Applied Statistics.

YI CHENG ZHANG (yi-cheng.zhang@unifr.ch) is a professor in Department of Physics at University of Fribourg, Switzerland. He also serves as the director of Alibaba Research Center for Complexity Sciences at Alibaba Business School, Hangzhou Normal University, and as an academic committee member for the Alibaba Research Institute of Alibaba Group. His research interests include big data, complex networks, and information economy. He has published widely, with over 200 articles in Proceedings of the National Academy of Sciences, Physical Review Letters, Physics Reports, Quantitative Finance, and other journals. 